\title{
Correlates of At-risk Gambling Behaviors of Homeless Youth
}

Magali Dufour $^{1^{*}}$, Élise Roy ${ }^{1}$, Jean-François Boivin ${ }^{2}$, Jean-François Boudreau ${ }^{1}$ and Marie Robert ${ }^{3}$

${ }^{1}$ Faculty of Medicine (Addiction Program), Université de Sherbrooke (Longueuil Campus), 150 Place Charles-Le Moyne, Suite 200, Longueuil QCJ4K 0A8 Canada ${ }^{2}$ Mc Gill University, Clinical Epidemiology Room A118, Jewish General Hospital 3755, Chemin de la Côte Ste-Catherine, Montréal, Qc, Canada

${ }^{3}$ Département de Psycho Education et de Psychologie, Université du Québec en Outaouais, 283 boul. Alexandre-Taché, Gatineau (Qc), J8x 3X7, Canada "Corresponding author: Magali Dufour, Faculty of Medicine (Addiction Program), Université de Sherbrooke (Longueuil Campus), 150 Place Charles-Le Moyne, Suite 200, Longueuil QC, J4K 0A8, Canada, Tel: +1 450-463-1835; E-mail: Magali.Dufour@usherbrooke.ca

Received date: January 10, 2014; Accepted date: April 28, 2014; Published date: April 30, 2014

Copyright: (c) 2014 Dufour M, et al. This is an open-access article distributed under the terms of the Creative Commons Attribution License, which permits unrestricted use, distribution, and reproduction in any medium, provided the original author and source are credited.

\begin{abstract}
Objective: This exploratory study aims to describe the gambling behaviors of 419 homeless youth.

Methods: Participants were divided into two groups: 1) those whose gambling behaviors did not present a risk $(n=366)$; and 2$)$ those whose gambling behaviors presented a risk $(n=53)$.

Results: In this homeless youth cohort, $12.6 \%$ exhibited gambling behaviors that could be considered at-risk. Compared to youth not having at-risk gambling behavior, youth with at-risk gambling behaviors were more likely to be male and be born outside of Canada. The at-risk participants were three times more likely to have a diagnosis of mental health disorder and two times more likely to report criminal activities as their main source of income.
\end{abstract}

Conclusions: These findings underline the importance of addressing all at-risk behaviors engaged in by homeless youth.

Keywords: Gambling behaviors; Homeless youth; Substance use; Mental health problems; Criminal behaviors; At-risk behaviour; Drug problem

\section{Introduction}

Over the years, various psychosocial theories have associated different at-risk behaviors, particularly, the general deviance model [1]. According to this model, deviant behavior during adolescence increases the risk of other deviant behaviors because of the associated contextual opportunities. Thus, youth exhibiting risk-taking behaviors, such as problematic alcohol use, are more likely to engage in other types of at-risk behaviors, including drug use or delinquency [2]. Recently, new substances that may lead to a problem of impulsivity have been incorporated into these general theories of addiction. In fact, several studies have observed a co-occurrence between alcohol and drugs consumption and gambling behaviors in youths under 21 years old [2-6]. Nowadays, youth gambling constitutes a cause for concern in the scientific community and is a central stake in public health. Gambling is one of the popular and most frequent at-risk behaviors teenagers and young adults participate in [7-9]. Several studies show that a high number of youth in the general population take part in gambling [3,10-14]. Gambling participation rates varying between $36 \%$ and $92 \%$ have been reported among adolescent and late adolescent (young adult) populations $[7-9,11,12,15,16]$. The prevalence of gambling problems appears to reach a peak at the end of the adolescence, in the 18- to-24-year-old group (called either young adult or late adolescent group) [3,13,17]. Studies looking at this age group, primarily conducted in the general population or among university students, report prevalence rates varying between $2 \%$ and $8 \%$ for problem gambling $[7,11-14,16]$. This is markedly higher than the prevalence observed among adults $(0.7 \%-1.8 \%)$ [18-21], underlining the vulnerability of the 18 -to-24-year olds with respect to this behavior [14,22].

Several studies have demonstrated a strong link between substance use and other risk-taking behaviors, such as gambling [4,11,16,23-25]. In fact, research shows that adolescent gamblers compared with nongamblers are more likely to consume alcohol or drugs [7,26,27], and are more likely to develop addiction problems [25,28-30]. In addition to a multitude of risk-taking behaviors, these young problem gamblers have been observed to exhibit more mental health problems, such as depression [25,31] and anxiety [32].

Until now, studies interested in the link between substance consumption and gambling have been conducted in the general population or among students. There has been little research conducted on more vulnerable youth, those exhibiting a number of risky behaviors such as homeless youth. In fact, no study, to our knowledge, has looked at documenting the importance of gambling behaviors among homeless youth. Furthermore, the link between gambling, substance use and mental health remains unknown among homeless youth. Nonetheless, these youth appear to be particularly at risk because of the harsh nature of their living condition that often implies involvement in informal economy, their specific characteristics $[33,34]$, and because they have few or no protective factors (family or school cohesiveness), known to help increase resiliency to gambling [35]. Also, homeless youth potentially have several vulnerability factors considered to be common in substance abuse problems and gambling problems, such as: a troubled family history, a low selfesteem, impulsivity, a history of physical or sexual abuse, delinquency and mental health problems [36-39]. 
This article aims to: 1) estimate the prevalence of at-risk gambling among homeless youth; and 2) document the association between atrisk gambling behaviors and the problems typically associated with problematic gambling, namely substance use problems, mental health problems and criminal activities [40,41].

\section{Methods}

This paper is based on secondary analyses done on a broader prospective cohort study that aimed to determine the links between residential trajectory, health problems and HIV risk behaviors among homeless youth. Within an exploratory context, gambling activities were assessed at study entry. Ethical approval was provided by "Comité d'éthique de la recherche en santé chez l'humain du Centre hospitalier universitaire de Sherbrooke".

\section{Participants}

Youth who were street-involved and currently homeless at baseline interview were eligible for the study. To be considered street-involved, a youth had to have used the services of Montreal (Quebec, Canada) street youth agencies regularly (three times or more) or been without a place to sleep more than once in the previous year $[42,43]$. Furthermore, youth were considered currently homeless if they had had nowhere to sleep in the previous 30 days, i.e., had spent at least one night in a place that was unfit for human habitation or in an emergency shelter. Youth who, on a temporarily basis, had spent at least one night at friends or acquaintances' places due to not having a personal place where to sleep (couch surfing) were also considered homeless [44]. Other entry criteria included being 18-25 years of age, English- or French- speaking, being able to provide informed consent and to complete an interviewer-administered questionnaire, and planning to stay in the Montreal area in the following year.

Of the 419 study participants, $19.8 \%$ were women and $80.2 \%$ were men (mean age: 21.8 years old; SD: 2.3 ). The average age at first homelessness episode was 16.2 years and participants had been homeless for approximately 2 years (median 2.0; IQR: 3.25 ). The majority of participants (90.7\%) were born in Canada and $83.8 \%$ were French speaking. Only $23.3 \%$ had a high school diploma.

\section{Procedures}

Between April 2006 and May 2007, study interviewers recruited participants during regular visits to all major street youth agencies in Montreal (Canada). These included drop-in centers, emergency shelters, or outreach vans offering a range of services such as food, short-term housing, and social and preventive healthcare services. Visit frequency, based on the number of youth served by each agency, ranged from once a month to three times a week. All youth present in the organization were invited to participate in the study. Those who accepted were given an appointment for their interview at the study office, located in the downtown area where most homeless youth hang out. The majority of interviews were done in the afternoon or early evening to minimize the possibility of participants being intoxicated. Interviews included the signing of a consent form, collection of contact information, and completion of an interviewer-administered questionnaire. Participants received a financial compensation (CAD $\$ 30)$ at the end of the interview.

\section{Measurements}

The study questionnaire typically took between 90 and 120 minutes to complete and covered various themes related to the objectives of the cohort study. Questions on socio-demographic characteristics included age, gender, country of birth and education $[42,43,45]$. With respect to gambling behavior, some authors assert that the frequency of gambling activities and the sum of money spent constitute important variables in defining gambling behaviors $[46,47]$. In fact, the risk of gambling related problems increases the more often one gambles and the more money spent in games of chance [47]. As gambling problems largely depend on financial losses, this variable occupies a central place in prevalence studies and often constitutes a marker for excessive gambling [48,49]. Therefore, in a context where no literature or data exists regarding homeless youth's gambling behaviors, three questions were used to examine participants' recent gambling behaviors: frequency of play, amount of money spent gambling and gambling-related debts. Nine types of gambling activities were examined: a) lottery tickets; b) casino table games; c) bingo; d) card games for money; e) horse race betting; f) video lottery terminals and slot machines; g) games of skill for money; $h$ ) dice for money; and i) sports betting. The frequency of past-month participation on each activity was assessed on a four-point scale: 1 ) never or less than once a month; 2 ) once a month; 3 ) once a week; and 4) every day. Furthermore, participants were asked to indicate the total sum of money spent gambling ("Keeping in mind the various types of gambling activities I have just mentioned, can you tell me how much money you spend betting or gambling on a monthly basis?"). Finally, gambling debts, a common consequence of gambling, was examined ("Do you currently have any gambling debts?"). Participants who confirmed having gambling debts were asked to indicate the total sum of the debt.

Based on their answers to these three questions, participants were grouped in one of two categories: participants presenting at-risk gambling behaviors and participants without at-risk gambling behavior. Having at-risk gambling behaviors was defined as having at least one of the following behaviors: a) gambling every day; b) having gambled $\$ 100$ or more in the previous month; and c) having gambling debts. The $\$ 100$ cut-off point was established based on existing youth gambling prevalence studies [4], and with the risk curves of gambling frequency and expenditure [47]. In fact, $\$ 100$ is more than twice the average sum of money spent by Quebecers monthly (\$37.50) [50], and beyond the optimal limit for low-risk participation of $1 \%$ of gross family income [47]. For youth living on the street, in precarious conditions, who most likely receive social assistance income, $\$ 100$ represents more than $25 \%$ of their average monthly income.

The presence of the following mental health problems was also assessed: alcohol/drug-related disorders (abuse and dependence), major depression, bipolar disorders, anorexia/bulimia, schizophrenia, anxiety disorders. Anxiety and alcohol/drug-related disorders were assessed using the CIDIS developed by Kovess et al. [51]. Questions for depression, bipolar disorder, anorexia and schizophrenia diagnoses were taken from the World Mental Health (WMH) Composite International Diagnostic Interview (CIDI; WMH-CIDI; version 2.1) [52]. All these instruments are well validated tools that can be administered by lay interviewers and produce psychiatric diagnoses according to the fourth version of the Diagnostic and Statistical Manual of Mental Health Disorders published by the American Psychiatric Association (DSM-IV) [53]. 
Page 3 of 8

Finally, criminal activities were evaluated using proxy based questions on criminal activities as main source of income in the previous three months. These included theft, fraud, selling of stolen goods, pimping and drug sales. Other sources of income (noncriminal) were marginal activities related to street economy such as survival sex, the sale of own goods, squeegee, begging, and conventional sources such as part-time or full-time work or governmental assistance.

\section{Analyses}

Descriptive analyses of socio-demographic characteristics, gambling behaviors, substance abuse or dependence (alcohol and drug), mental disorders, and income sources were performed. Means, medians, and proportions were calculated. Correlates of at-risk gambling behaviors were examined using logistic regression analyses. Variables with pvalue $\leq 0.20$ in univariate analyses were entered into initial multivariate models. Following the purposeful selection procedure [54], significant variables at the $5 \%$ level as well as those that showed a confounding effect on significant co-variables were retained in the final multivariate models. Because of parsimony concern, having one mental disorder or more was the only variable entered in the logistic regression.

\section{Results}

\section{Gambling behaviors}

Almost a third (33.4\%) of participants had gambled in the previous month $(35.4 \%$ of men vs. $25.3 \%$ of women, $\mathrm{p}=0.08$ ). Approximately $5.7 \%$ gambled daily and $15.5 \%$ gambled on a weekly basis. The most popular gambling activities included lottery tickets, video lottery terminals and slot machines, playing cards for money, and games of skill for money.

With respect to the amount of money spent gambling in the previous month, $11.9 \%$ had spent $\$ 100$ or more and the average amount of money spent was $\$ 215$ (max: $\$ 5000)$. Among those who reported having gambled $(\mathrm{n}=140)$ in the past month, $2.9 \%$ reported gambling debts varying between $\$ 20$ and $\$ 500$.

\section{Prevalence of at-risk gambling behaviors}

The overall prevalence of gambling behaviors considered at-risk in the past month was $12.6 \%$ (14.3\% of men vs. $6.0 \%$ of women, $\mathrm{p}=0.04)$.Specifically, 53 participants reported having at least one atrisk behavior: 50 participants $(11.9 \%)$ had spent $\$ 100$ or more in the past month, $24(5.7 \%)$ had participated in at least one gambling activity on a daily basis, and four participants (1.0\%) had gambling debts.

\begin{tabular}{|c|c|c|c|}
\hline & No-risk group $(n=366)$ & At-risk group $(n=53)$ & $P$ value \\
\hline Alcohol $\dagger$ & $80.1 \%$ & $79.2 \%$ & 0.88 \\
\hline Daily alcohol use $\dagger$ & $18.3 \%$ & $13.2 \%$ & 0.47 \\
\hline Marijuana† & $79.2 \%$ & $79.2 \%$ & 0.76 \\
\hline Hallucinogenic (acid/PCP/mushrooms) $\dagger$ & $23.8 \%$ & $17.0 \%$ & 0.37 \\
\hline Cocaine/crack/freebase $\dagger$ & $39.1 \%$ & $47.2 \%$ & 0.28 \\
\hline
\end{tabular}

The at-risk group had spent, on average, $\$ 593$ in the previous month (range: $\$ 20$ to $\$ 5000$, median: $\$ 300$ ) in comparison with an average of $\$ 4.50$ (range $\$ 0$ to $\$ 70$, median: $\$ 0$ ) for the non-risk group. A higher proportion ofat-risk gambling behavior participants had taken part in each type of gambling activity compared to their non-risk counterparts (Table 1) and the number of types of gambling activities involved in over the previous month was also higher $(0.4$, non-risk vs. 2.8, at-risk, sum of ranks=68138.5 vs. 19851.5, Mann-Whitney $\mathrm{U}=977.5, \mathrm{p}<0.001$ ). The most popular activity among the at-risk group was video lottery terminals and other slot machines, followed by lottery tickets.

\begin{tabular}{|c|c|c|}
\hline & $\begin{array}{l}\text { No-risk } \\
(n=366)\end{array} \quad$ group & At-risk group ( $n=53$ ) \\
\hline Lottery tickets & $12.8 \%$ & $60.4 \%$ \\
\hline Casino & $0.8 \%$ & $30.2 \%$ \\
\hline Bingo & $1.1 \%$ & $13.2 \%$ \\
\hline Card playing for money & $4.4 \%$ & $35.8 \%$ \\
\hline Horse race betting & $0.3 \%$ & $5.7 \%$ \\
\hline $\begin{array}{l}\text { Video lottery terminals or slot } \\
\text { machines }\end{array}$ & $7.7 \%$ & $66.0 \%$ \\
\hline Skill games for money & $2.5 \%$ & $30.2 \%$ \\
\hline Dice for money & $3.0 \%$ & $24.5 \%$ \\
\hline Sports betting & $2.5 \%$ & $18.9 \%$ \\
\hline
\end{tabular}

Table 1: Gambling behaviors in the previous month

\section{Psychoactive substance use and at-risk gambling behavior}

The majority of the study participants reported having consumed alcohol or recreational drugs in the previous month (Table 2). Logistic regression analysis, controlling for gender, demonstrated that there was no statistical difference for alcohol and recreational drug use between the at-risk group and the non-risk group. The psychoactive substance use profiles were similar with respect to the drugs used, regular drug used, daily alcohol consumption, or use by injection. In the past month, $60.4 \%$ of the at-risk youth had used several substances and the average number of recreational drugs used was 2.2. Furthermore, $13.2 \%$ of the at-risk youth reported having injected themselves with drugs in the previous month and $13.2 \%$ had consumed alcohol daily. As for diagnoses, both groups were also similar in that $75.5 \%$ of the youth with at-risk gambling behaviors and $71.9 \%$ of the youth with non-risk gambling behaviors had substancerelated problems in the previous year $(\mathrm{p}=0.45)$. 
Citation: Dufour M, Roy E, Boivin JF, Boudreau JF, Robert M (2014) Correlates of At-risk Gambling Behaviors of Homeless Youth. J Addict Res

Page 4 of 8

\begin{tabular}{|l|l|l|l|}
\hline Heroin $\dagger$ & $12.6 \%$ & $7.5 \%$ & 0.47 \\
\hline Heroin and cocaine mixture $\dagger$ & $1.4 \%$ & $1.9 \%$ & 0.6 \\
\hline Solvent/glue $\dagger$ & $1.9 \%$ & $1.9 \%$ & 0.9 \\
\hline Amphetamines (including ecstasy) $\dagger$ & $39.1 \%$ & $41.5 \%$ & 0.73 \\
\hline Medication used for the buzz $\dagger$ & $21.3 \%$ & $20.8 \%$ & 0.97 \\
\hline Injection of drugs $\dagger$ & $18.9 \%$ & $13.2 \%$ & 0.46 \\
\hline Multiple drug use & $64.2 \%$ & $60.4 \%$ & 0.66 \\
\hline Numbers of types of drugs used & 2.2 & 2.2 & 0.92 \\
\hline Regular drug used $(\geq 3$ times per week) $\dagger$ & $67.8 \%$ & $66.0 \%$ & 0.58 \\
\hline Problems related to substance used & $71.9 \%$ & $75.5 \%$ & 0.45 \\
\hline Alcohol abuse-dependence $\ddagger$ & $33.6 \%$ & $32.1 \%$ & 0.87 \\
\hline Drug abuse-dependence $\ddagger$ & $63.7 \%$ & $71.7 \%$ & 0.18 \\
\hline
\end{tabular}

Table 2: Comparison of psychoactive substance use; $\mathrm{P}$-value of logistic regression, controlling for gender; $\dagger$ : in the past month, $\ddagger:$ in the past year

\section{Correlates of at-risk gambling behaviors}

Results of univariate analyses highlight significant differences in socio-demographic characteristics and in income sources between the two groups of participants. Proportion of men, born outside of Canada and whose main sources of income are based on criminal activities are higher among the at-risk gambling behaviors group. No significant association was found between having at-risk gambling behaviors and having a substance use or a mental health disorder. However, results show a tendency for youth diagnosed with at least one mental health disorder to be at higher risk for experiencing at-risk gambling behaviors $(\mathrm{p}=0.074)$ (Table 3$)$.

\begin{tabular}{|l|l|l|l|}
\hline & At risk/total & At risk rate & P value \\
\hline Gender & & & \\
\hline Male & $48 / 336$ & $14.3 \%$ & \\
\hline Female & $5 / 83$ & $6.0 \%$ & 0.043 \\
\hline Country of birth & & & \\
\hline Outside Canada & $10 / 39$ & $25.6 \%$ & \\
\hline Canada & $43 / 380$ & $11.3 \%$ & 0.019 \\
\hline Scholarship & & $12.1 \%$ & \\
\hline No high school & $39 / 322$ & $14.4 \%$ & 0.547 \\
\hline $\begin{array}{l}\text { High school or } \\
\text { more }\end{array}$ & $14 / 97$ & & \\
\hline $\begin{array}{l}\text { Main source of } \\
\text { income }\end{array}$ & & $23.7 \%$ & \\
\hline Criminal & $18 / 76$ & $10.2 \%$ & 0.001 \\
\hline Non-Criminal & $35 / 343$ & $13.2 \%$ & \\
\hline $\begin{array}{l}\text { Problems related } \\
\text { to substance used }\end{array}$ & $40 / 303$ & & \\
\hline Yes & & & \\
\hline
\end{tabular}

\begin{tabular}{|c|c|c|c|}
\hline No & $13 / 116$ & $11.2 \%$ & 0.583 \\
\hline $\begin{array}{l}\text { Alcohol abuse or } \\
\text { dependence }\end{array}$ & & & \\
\hline Yes & $17 / 140$ & $12.1 \%$ & \\
\hline No & $36 / 279$ & $12.9 \%$ & 0.825 \\
\hline $\begin{array}{l}\text { Drug abuse or } \\
\text { dependence }\end{array}$ & & & \\
\hline Yes & $38 / 271$ & $14.0 \%$ & \\
\hline No & $15 / 148$ & $10.1 \%$ & 0.253 \\
\hline $\begin{array}{l}\text { Anxiety disorders } \\
\text { (phobias, panic } \\
\text { disorder, } \\
\text { generalized } \\
\text { anxiety disorder) }\end{array}$ & & & \\
\hline Yes & 20/121 & $16.5 \%$ & \\
\hline No & $33 / 298$ & $11.1 \%$ & 0.128 \\
\hline $\begin{array}{l}\text { Eating disorder } \\
\text { (anorexia, } \\
\text { bulimia) }\end{array}$ & & & \\
\hline Yes & $0 / 3$ & $0 \%$ & \\
\hline No & $52 / 415$ & $12.5 \%$ & 1 \\
\hline $\begin{array}{l}\text { Affective } \\
\text { disorders (major } \\
\text { depression, } \\
\text { bipolar disorder, } \\
\text { dysthymic } \\
\text { disorder) }\end{array}$ & & & \\
\hline Yes & $16 / 93$ & $17.2 \%$ & \\
\hline No & $37 / 326$ & $11.3 \%$ & 0.134 \\
\hline $\begin{array}{l}\text { Psychotic } \\
\text { disorders }\end{array}$ & & & \\
\hline
\end{tabular}


Page 5 of 8

\begin{tabular}{|l|l|l|l|}
\hline $\begin{array}{l}\text { (schizophrenia, } \\
\text { delusional) }\end{array}$ & & & \\
\hline Yes & $0 / 10$ & $0 \%$ & \\
\hline No & $53 / 409$ & $13 \%$ & 0.622 \\
\hline Diagnostica & & $6.4 \%$ & \\
\hline $\begin{array}{l}1 \quad \text { diagnostic or } \\
\text { more }\end{array}$ & $5 / 78$ & $13.8 \%$ & 0.074 \\
\hline No diagnostic & $47 / 340$ & & \\
\hline
\end{tabular}

resources available to them may have possibly increased their use of gambling as subsistence strategy to gain money and improve their living conditions [56]. This hypothesis is based on research results on gambling motivations of homeless adults, which are often associated with the need to feel equal, to have some comfort and to get off the street [57-58].

The data set allowed an opportunity to explore, for the first time, the characteristics of homeless youth who reported at-risk gambling behavior. While the majority of these youth reported very few gambling behaviors in the previous month, a significant minority (12.6\%) presented risky gambling behaviors. The at-risk gambling behavior group had spent, on average, $\$ 593$, which represents more than 15 times the amount of money spent by Quebecers (\$37.50) on a monthly basis [50]. Furthermore, the at-risk group participants took part in a greater number of gambling activities, the most popular being video lottery terminals and other types of slot machines, while $7.5 \%$ of youth in that group had gambling debts. These findings suggest that certain homeless youth might have problematic gambling behaviors. Moreover, these results corroborate findings from previous studies conducted on homeless adults who presented a higher prevalence of gambling behaviors and a preference for video lottery terminals [56-59]. The potential vulnerability of homeless youth should be further explored in order to better identify the characteristics of homeless youth at risk of developing gambling problems.

Contrary to what has been observed in studies conducted among university students $[11,17,22,55]$, no difference was found in proportion of participants with a diagnosis of drug or alcohol abuse or dependency between the two groups. This lack of difference may very well be explained by the elevated prevalence of substance abuse/ dependence among homeless youth [60-62].

Results on correlates of at-risk gambling behavior show a greater proportion of males and youth born outside of Canada in the at-risk group $[4,11,22]$. Since an increased frequency of gambling goes hand in hand with increased money spent on gambling, criminal activities are often a way of getting important amount of money. In fact, criminal activities may bring in more money than the marginal and conventional activities. However, criminal activities can worsen the severity of gambling-related problems63. In this cohort of homeless youth, criminal activities were substantially more common in the atrisk group (23.7\%). Although it is impossible to determine a causal relationship, these data are consistent with other observations on delinquency among problem gamblers [63-65]. Given the exploratory nature of the present study, further studies are needed to determine the links between gambling and criminality in homeless youth. In fact, it would be interesting to compare the profile of this at-risk group to that of the adolescents presenting the most severe externalizing behaviors [66].

Despite the presence of a higher proportion of youth diagnosed with at least one mental health disorder in the at-risk group, the difference found was not statistically significant. Furthermore, no association between specific mental health diagnosis (depression, anxiety) and at-risk gambling behaviors was found. These data do not corroborate clinical and epidemiological studies observing association between depression or anxiety and problematic gambling [32,67-69]. Lack of association between anxiety and depression diagnosis and atrisk gambling behavior might be caused by the use of a robust clinical diagnosis in the present study, while other studies often use selfreported data or less robust screening tools. However, the final regression model reveals that participants in the at-risk gambling 
Page 6 of 8

behaviors group are three times more likely to experience at least one mental health disorder, which is in line with previous research results underlying the risky nature of mental health disorders for gambling problems [41].

In summary, these results underline the presence of a significant proportion of homeless youth exhibiting a constellation of at-risk behaviors. In addition to a problematic use of alcohol and other drugs, some youth also participate in gambling activities. Youth who play more frequently and who spend significant amounts of money have specific characteristics when compared to those who do not report atrisk gambling behaviors. Males and youth born outside of Canada are almost three times more likely to be in the at-risk group. Youth whose main sources of income are criminality-based are two times more likely to be in the at-risk group while youth with at least one mental health diagnosis are three times more likely to be in this group.

These results suggest that at-risk gambling is associated with several risk behaviors and with other substance use problems4. These findings also underline the importance of considering the constellation of atrisk behaviors in homeless youth for both prevention and treatment interventions. Since at-risk behaviors are probably a result of common physiological, psychological, familial and even environmental predispositions, it is important to address and to work on the comorbidity and the interrelations between these problem behaviors. Moreover, this therapeutic work, where all the at-risk behaviors are addressed in an integrated way, requires not only a personalized intervention plan, but also brief innovative interventions adapted to the life conditions of these youth. A first approach could be made by street workers, who could integrate questions regarding youth's gambling habits, to make them see the environment's openness to address these issues. Finally, additional studies need to be conducted in order to better understand the gambling behaviors of homeless youth and the relationship between these behaviors and other at-risk behaviors.

This study has several important limitations to be considered when interpreting the results. First, the scope of the results is limited by the lack of use of a validated questionnaire allowing for the establishment of a diagnosis of pathological gambling. Although it is difficult to use validated instruments such as the DSM-IV with this marginal population due to their inherent characteristics, namely the fact that certain consequences of gambling (such as lying to family or potentially losing a job) are not likely to be measurable among homeless youth in unstable living conditions, a robust diagnosis would allow for a better evaluation of the prevalence of gambling problems in this population. Moreover, the use of a validated questionnaire would allow for a better understanding of the consequences of the gambling behaviors for these youth on the different areas of their life. Furthermore, the reference period used in this study (previous month) is not necessarily representative of the participants' gambling behaviors in the previous year. Using a validated instrument such as the Canadian Problem Gambling Index (CPGI) measuring the gambling behaviors over the previous year would allow for a better understanding of gambling problems [70]. Due to the limited number of questions related to gambling behaviors in our study, it was impossible to go beyond the description of gambling behaviors. Lastly, since this data rests on self-reported behaviors, it is difficult to estimate the validity of the youths' reports concerning the money spent gambling, particularly since it's known that gamblers have a tendency to underestimate their spending [46]. Despite these limitations, this first set of data collected among a neglected population underlines the need to continue investigating gambling behaviors of homeless youth.

\section{Acknowledgements}

Funding was provided by the Canadian Institutes of Health Research. The authors would like to thank the street youth and street youth agencies that collaborated in this study and all members of the research team. A frequent SPU was associated with increased severity of substance dependence compared to non/occasional SPU.

When a substance is a trigger for a second one, it reveals the severity of dependence to that second substance.

\section{Funding}

Swiss National Science Foundation FN 33CS30_139467

\section{References}

1. Donovan JE, Jessor R (1985) Structure of problem behavior in adolescence and young adulthood. J Consult ClinPsychol 53: 890-904.

2. Turner NE, Ialomiteanu A, Paglia-Boak A, Adlaf EM (2011) A typological study of gambling and substance use among adolescent students. Journal of Gambling Issues 25: 88-107.

3. Barnes GM, Welte JW, Hoffman JH, Tidwell MC (2011) The cooccurrence of gambling with substance use and conduct disorder among youth in the United States. Am J Addict 20: 166-173.

4. Goldstein AL, Walton MA, Cunningham RM, Resko SM, Duan L (2009) Correlates of gambling among youth in an inner-city emergency department. Psychol Addict Behav 23: 113-121.

5. Wanner B, Vitaro F, Carbonneau R, Tremblay RE (2009) Cross-lagged links among gambling, substance use, and delinquency from midadolescence to young adulthood: additive and moderating effects of common risk factors. Psychol Addict Behav 23: 91-104.

6. Vitaro F, Wanner B, Charbonneau R, Tremblay RE (2007) La pratique des jeux de hasard et d'argent, les comportementsdélinquants et la consommationproblématique de substances psychotropes : une perspective développementale. Criminologie 40: 59-77.

7. Brunelle N, Leclerc D, Cousineau MM, Dufour M, Gendron A, et al. (2012) Internet gambling, substance use, and delinquent behavior: an adolescent deviant behavior involvement pattern. Psychol Addict Behav 26: 364-370.

8. Gupta R, Derevensky J (2008) Gambling practices among youth: Etiology, prevention and treatment. In CA Essau (edn) Adolescent addiction: Epidemiology, assessment and treatment, (pp. 207-230). London, United Kingdom: Elsevier.

9. Martin I, Gupta R, Derevensky J (2008) Participation aux jeux de hasard et d'argent. In DubéGaëtane et autres. Enquêtequébécoisesur le tabac, l'alcool, la drogue et le jeu chez les élèves du secondaire, Québec, Institut de la statistique du Québec, 149-181.

10. Wickwire EM, Whelan JP, West R, Meyers A, McCausland C, et al. (2007) Perceived availability, risks, and benefits of gambling among college students. J Gambl Stud 23: 395-408.

11. Engwall D, Hunter R, Steinberg M (2004) Gambling and other risk behaviors on university campuses. J Am Coll Health 52: 245-255.

12. Huang JH, Boyer R (2007) Epidemiology of youth gambling problems in Canada: a national prevalence study. Can J Psychiatry 52: 657-665.

13. Welte JW, Barnes GM, Tidwell MC, Hoffman JH (2008) The prevalence of problem gambling among U.S. adolescents and young adults: results from a national survey. J Gambl Stud 24: 119-133.

14. Williams RJ, Connolly D, Wood RT, Nowatzki N (2006) Gambling and Problem Gambling in a Sample of University Students. Journal of Gambling Issues. 
15. Jacobs DF (2004) Youth gambling in North America: An analysis of long term trends and future prospects. In DerevenskyJefferey and Gupta Rina (eds) Gambling Problems in Youth: Theoretical and Applied Perspectives. Kluwer Academic/Plenum Publishers, New York.

16. Brunelle N, Leclerc D, Cousineau MM, Dufour M, Gendron A, et al. (2012) Internet gambling, substance use, and delinquent behavior: an adolescent deviant behavior involvement pattern. Psychol Addict Behav 26: 364-370.

17. Winters KC, Stinchfield RD, Botzet A, Anderson N (2002) A prospective study of youth gambling behaviors. Psychol Addict Behav 16: 3-9.

18. Cox BJ, Yu N, Afifi TO, Ladouceur R (2005) A national survey of gambling problems in Canada. Can J Psychiatry 50: 213-217.

19. Ladouceur R, Jacques C, Chevalier S, Sévigny S, Hamel, et al. (2002) Prévalence des habitudes de jeu et du jeupathologique au Québec en 2002, Québec et Montréal, Université Laval et Institut national de santé publique du Québec.

20. Stucki S, Rihs-Middel M (2007) Prevalence of adult problem and pathological gambling between 2000 and 2005: an update. J Gambl Stud 23: 245-257.

21. Kairouz S, Nadeau L, Paradis C (2010) Enquête ENHJEU-Québec: Portrait du jeu au Québec: Prévalence, incidence et trajectoiressurquatre ans. Rapport remis au Fonds de recherchesur la société et la culture (FQRSC), Université Concordia.

22. Stuhldreher WL, Stuhldreher TJ, Forrest KY (2007) Gambling as an emerging health problem on campus. J Am Coll Health 56: 75-83.

23. Barnes GM, Welte JW, Hoffman JH, Tidwell MC (2009) Gambling, alcohol, and other substance use among youth in the United States. J Stud Alcohol Drugs 70: 134-142.

24. LaBrie RA, Shaffer HJ, LaPlante DA, Wechsler H (2003) Correlates of college student gambling in the United States. J Am Coll Health 52: 53-62.

25. Lynch WJ, Maciejewski PK, Potenza MN (2004) Psychiatric correlates of gambling in adolescents and young adults grouped by age at gambling onset. Arch Gen Psychiatry 61: 1116-1122.

26. Duhig AM, Maciejewski PK, Desai RA, Krishnan-Sarin S, Potenza MN (2007) Characteristics of adolescent past-year gamblers and nongamblers in relation to alcohol drinking. Addict Behav 32: 80-89.

27. Potenza MN, Steinberg MA, Wu R (2005) Characteristics of gambling helpline callers with self-reported gambling and alcohol use problems. J Gambl Stud 21: 233-254.

28. Desai RA, Maciejewski PK, Pantalon MV, Potenza MN (2005) Gender differences in adolescent gambling. Ann Clin Psychiatry 17: 249-258.

29. Hardoon KK, Gupta R, Derevensky JL (2004) Psychosocial variables associated with adolescent gambling. Psychol Addict Behav 18: 170-179.

30. Langhinrichsen-Rohling J, Rohling ML, Rohde P, Seeley JR (2004) The SOGS-RA vs. the MAGS-7: prevalence estimates and classification congruence. J Gambl Stud 20: 259-281.

31. Feigelman W, Gorman BS, Lesieur H (2006) Examining the relationship between at-risk gambling and suicidality in a national representative sample of young adults. Suicide Life Threat Behav 36: 396-408.

32. el-Guebaly N, Patten SB, Currie S, Williams JV, Beck CA, et al. (2006) Epidemiological associations between gambling behavior, substance use \& mood and anxiety disorders. J Gambl Stud 22: 275-287.

33. Baron SW (1999) Street Youths and Substance Use. The Role of Background, Street Lifestyle, and Economic Factors. Youth \& Society 31: 3-26.

34. Ammerman SD, Ensign J, KirznerRn (2004) Homeless Young Adults Ages 18-24: Examining Service Delivery Adaptations. National Health Care for the Homeless Council, Nashville.

35. Dickson L, Derevensky JL, Gupta R (2008) Youth Gambling Problems: Examining Risk and Protective Factors. International Gambling Studies 8: $25-47$.

36. Barnes GM, Welte JW, Hoffman JH, Dintcheff BA (1999) Gambling and alcohol use among youth: influences of demographic, socialization, and individual factors. Addict Behav 24: 749-767.
37. Barnes GM, Welte JW, Hoffman JH, Dintcheff BA (2002) Effects of alcohol misuse on gambling patterns in youth. J Stud Alcohol 63: 767-775.

38. Stinchfield RD, Winters KC (1999) Adolescent Gambling: A Review of Prevalence, Risk Factors and Health Implications. Annals of the American Academy of Political and Social Science 556: 172-185.

39. Shead NW, Derevensky JL, Gupta R (2010) Risk and protective factors associated with youth problem gambling. Int J Adolesc Med Health 22: 39-58.

40. Barnes GM, Welte JW, Hoffman JH, Dintcheff BA (2005) Shared predictors of youthful gambling, substance use, and delinquency. Psychol Addict Behav 19: 165-174.

41. Johansson A, Grant JE, Kim SW, Odlaug BL, Götestam KG (2009) Risk factors for problematic gambling: a critical literature review. J Gambl Stud 25: 67-92.

42. Roy E, Haley N, Leclerc P, Cédras L, Blais L, et al. (2003) Drug injection among street youths in Montreal: predictors of initiation. J Urban Health 80: 92-105.

43. Haley N, Roy E, Leclerc P, Boudreau JF, Boivin JF (2004) HIV risk profile of male street youth involved in survival sex. Sex Transm Infect 80: 526-530.

44. Gaetz S (2010) Homeless Hub - What is Homelessness?

45. Institut de la statistique du Québec. Collection la santé et le bien-être. Gouvernement du Québec. Enquêteauprès de la clientèle des ressources pour personnesitinérantes des régions de Montréal-centre et de Québec, 1998-1999. Montréal, Québec: Les publications du Québec.

46. Blaszczynski A, Ladouceur R, Goulet A, Savard C (2008) Difference in Monthly versus Daily Evaluations of Money Spent on Gambling and Calculation Strategies. Journal of Gambling Issues.

47. Currie SR, Hodgins DC, Wang J, el-Guebaly N, Wynne H, et al. (2006) Risk of harm among gamblers in the general population as a function of level of participation in gambling activities. Addiction 101: 570-580.

48. Walker MB, Dickerson MG (1996) The prevalence of problem and pathological gambling: A critical analysis. J Gambl Stud 12: 233-249.

49. Williams R, Wood R (2004) Final report: The demographic sources of Ontario gaming revenue. Guelph, Ontario, Canada: Ontario Problem Gambling Research Centre.

50. Proudfoot S (2008) Canadians lost $\$ 13.6 \mathrm{~B}$ to gambling in 2007: report. Canwest News Service..

51. Kovess V, Fournier L, Lesage AD, Lebigre FA, Caria A (2001) Two validation studies of the CIDIS: a simplified version of the Composite International Diagnostic Interview. Psychiatric Networks 4: 10-24.

52. Kessler RC, Ustun TB (2004) The World Mental Health (WMH) Survey Initiative version of the World Health Organization (WHO) Composite International Diagnostic Interview (CIDI). The International Journal of Methods in Psychiatric Research 13: 93-121.

53. American Psychiatric Association (2000) DSM-IV, Manuel diagnostique et statistique des troubles mentaux (4thedn). Paris, Masson.

54. Hosmer DW, Lemeshow S (1989) Applied Logistic Regression. New York: Wiley.

55. Winters KC, Bengston P, Dorr D, Stinchfield R (1998) Prevalence and Risk Factors of Problem Gambling Among College Students. Psychology of Addictive Behaviors 12: 127-135.

56. Shaffer HJ, Freed CR, Healea D (2002) Gambling disorders among homeless persons with substance use disorders seeking treatment at a community center. PsychiatrServ 53: 1112-1117.

57. Talbot C (2004) Gambling and Homelessness. A case management resource, Adelaide (South Australia), UnitingCare Wesley.

58. Rogers N (2005) Safe as Houses? An Exploration of The Link Between Gambling and Homelessness. Gouvernment of South Australia: Department for Families and Communities.

59. Antonetti E, Horn M (2001) Gambling The Home Away. A Study of the Impact of Gambling on Homelessness. Melbourne, Hanover Welfare Services. 
Citation: Dufour M, Roy E, Boivin JF, Boudreau JF, Robert M (2014) Correlates of At-risk Gambling Behaviors of Homeless Youth. J Addict Res Ther S10: 007. doi:10.4172/2155-6105.S10-007

Page 8 of 8

60. Adlaf EM, Zdanowicz YM (1999) A cluster-analytic study of substance problems and mental health among street youths. Am J Drug Alcohol Abuse 25: 639-660.

61. Keyes KM, Martins SS, Hasin DS (2008) Past 12-month and Lifetime Comorbidity and Poly-drug Use of Ecstasy Users among Young Adults in the United States: Results from the National Epidemiologic Survey on Alcohol and Related Conditions. Drug Alcohol Depend 97: 139-149.

62. Roy E, Haley N, Leclerc P, Lemire N, Boivin JF, et al. (2000) Prevalence of HIV infection and risk behaviours among Montreal street youth. Int J STD AIDS 11: 241-247.

63. Ledgerwood DM, Weinstock J, Morasco BJ, Petry NM (2007) Clinical Features and Treatment Prognosis of Pathological Gamblers With and Without Recent Gambling-Related Illegal Behavior. J Am Acad Psychiatry Law 39: 294-301.

64. Meyer G, Stadler MA (1999) Criminal Behavior Associated with Pathological Gambling. J Gambl Stud 15: 29-43.

65. Potenza MN, Steinberg MA, McLaughlin SD, Rounsaville BJ, O'Malley SS (2000) Illegal behaviors in problem gambling: analysis of data from a gambling helpline. J Am Acad Psychiatry Law 28: 389-403.
66. Vaughn MG, Salas-Wright CP, DeLisim M, Maynard BR (2014) Violence and Externalizing Behavior Among Youth in the United States: Is There a Severe 5\%? Youth Violence and Juvenile Justice 12: 3-21.

67. Desai RA, Potenza MN (2008) Gender differences in the associations between past-year gambling problems and psychiatric disorders. Soc Psychiatry PsychiatrEpidemiol 43: 173-183.

68. Petry NM (2000) Psychiatric symptoms in problem gambling and nonproblem gambling substance abusers. Am J Addict 9: 163-171.

69. Westphal JR, Johnson LJ (2007) Multiple Co-occuring Behaviours among Gamblers in Treatment: Implication and Assessment. International Gambling Studies 7: 73-99.

70. Ferris J, Wynne H (2001) The Canadian Problem Gambling Index: Final Report. Submitted for the Canadian Centre on Substance Abuse.
This article was originally published in a special issue, entitled: "Addictions with Co-occurring Problems", Edited by Marie-Josee Fleury, Centre de réadaptation en dépendance de Montréal (CRDM)-Institut universitaire, Canada 